\title{
An Enhanced Zero Crossing Based HVAC Phase Synchronous Inverter for Electrostatic Generator in Microgrid Systems
}

\author{
Tawfikur Rahman , S. M. A. Motakabber, M. I. Ibrahimy and M. Wahidur Rahman \\ Department of Electrical and Computer Engineering \\ International Islamic University Malaysia, Kuala Lumpur, Malaysia \\ e-mail: tawfikurr@gmail.com
}

\begin{abstract}
Electrostatic Generator (ESG) faced far more challenges when it integrated with the phase synchronous inverter systems as ESG can generate high voltage DC and very low current. This high DC voltage needs to be converted and also low current of the ESG have to be increased for microgrid system which works generally performed by power inverter circuit. Therefore, phase synchronous inverter (PSI) is presented, to increase the inverter output current, with the aid of zero crossing voltage source controller. However, there is an issue to design the inverter which are harmonic distortion and phase angle. In this paper, a zero-crossing circuit is developed to synchronize inverter and microgrid phase and according to the simulation result, the phase angle is $3.22^{\circ}$. In addition, an LCL filter is designed to reduce the harmonic distortion. The performance of the PSI had been demonstrated by modeling it in MATLAB2016a software. The considered parameter of the design is input voltage $10 \mathrm{kV}$, switching frequency $60 \mathrm{~Hz}$, modulation index 0.85 and cut-off frequency $33 \mathrm{~Hz}$. The simulation results show that the designed inverter can greatly improve the system stability and robustness of the microgrid system and the obtained PSI system efficiency is $97.35 \%$ that performed better compared to the related inverter techniques.
\end{abstract}

Keywords: PSI; zero crossing; controller; LCL filter; transformer; microgrid;

\section{Introduction}

At present, there is a huge demand to transmit high power in the microgrid systems. But the power delivering to the microgrid system is getting more and more stressed due to the limitation on the power delivery capability. This complicates in building new microgrid infrastructures which lead to blackouts [1]. In addition, micro grid research has gained huge interest due to the reduced consumption of fossil fuel. ESG can further overcome this issue as it generates high voltage DC but only required the small size of the generator. Most of the microgrid system uses AC supply but, which required synchronized phase. To solve this issue PSI system is needed. PSI has a significant impact to integrate different types of renewable energy sources to the microgrid. Different inverter topology and various sophisticated control methodologies like zero crossing based phase synchronous inverter for sustainable energy are studied in detail in [2] to integrate different energy sources such as wind power and photovoltaic cell etc., in the microgrid and to ensure efficient operation of the microgrid systems [2-3].

In [3], there has an extensive research has done on three-phase pulse-width-modulated (PWM) inverters to integrate the renewable energy sources with three-phase grids. Three-phase unbalanced grid inverter circuit which interfaces with microgrid is documented in [4-3]. To reduce phase angle and ripple current, a series-parallel compensator has proposed in balanced and unbalanced three-phase microgrid system in [5-6]. To synchronize the phase in between inverter and microgrid system, simple zero crossing technique is used, but this technique for phase synchronization is still a critical issue [7].

In this paper, a zero-crossing based voltage source phase synchronous inverter has proposed to synchronize the inverter and microgrid phase, magnitude and frequency. This proposed design is three phase based system which increases the power supply capability of the overall power network. This inverter required six switching IGBT modules for switching topology during the overall operation [8]. A zero crossing is an electric component with a voltage is driven oscillator that can adjust between inverter and microgrid phase [9]. In addition, to reduce the harmonic distortion, in the existing design has presented L, LC and LCL filter but 
they have still problems or high harmonic distortion. Therefore, an improved LCL filter has designed [10].

This controller circuit is presented zero crossing based voltage source controller circuit that reduces the switching loss and for phase synchronization with frequency control. It has a feedback component which has designed in order to allow a circuit to synchronize the frequency of the phase of it's on the clock with an external timing signal [11]. The focus of this paper is on the three-phase inverter interfacing the renewable energy sources to the microgrid. At the same time adjusts the phase of the oscillator's signal of the clock for the same phase of the reference signal. To optimize the overall power circuit of the microgrid, a cost-effective solution for the power circuit is to replace the multilevel switch based three phase inverters with a six-switch module based three phase inverter topologies. The six-switch module inverter, having a lower number of switches has been studied for the possibility of reducing the inverter cost.

The paper is prepared as follows. The PSI basics provided in Section II. Overview inverter switching method, including switching topology in Section III. The discussion and design of zero crossing technique in Section IV. Section V, Section VI and Section VII are provided in the LCL filter, transformer and microgrid design. Simulation results are shown in Section VIII. Conclusions are presented in Section IX.

\section{Phase Synchronous Inverter}

PSI is an electronic switching base power inverter that is synchronous between inverter and microgrid phase with same frequency, voltage, current and angle by using an appropriate transformer for balancing voltage. Figure 1 shows the block diagram of the zero-crossing based phase synchronous inverter.

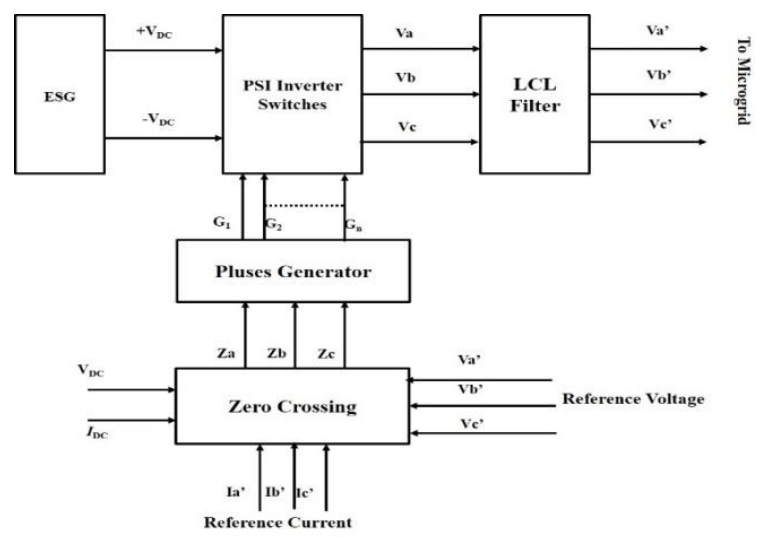

Figure 1. Basic block-diagram of the proposed PSI systems

This system consists of ESG, electronic switches, zero-crossing, voltage source controller, output $L C L$ filter and microgrid. Input sources are considered of $\pm 5 \mathrm{k} V_{D C}$ voltage form ESG which is converted into AC voltage with the suitable step-up $Y-\Delta$ transformer. A zerocrossing circuit detected microgrid reference voltage and current to generate the zero-crossing signal while pulse controllers generate gate pulses to operate the electronic switch. In addition, a low pass LCL filter is used to decrease the noise and to synchronize the phase [12].

\section{PSI Switching Methods}

The $3 \varphi \mathrm{PSI}$ switching module block diagram are shown in Figure 2. In this design, two input DC voltage sources are assumed from ESG such as $+V_{d c / 2}=5000 \mathrm{Vdc}$ and $-V_{d c / 2}=-$ $5000 V_{d c}$. The input source terminals $+V_{d c / 2}$ and $-V_{d c / 2}$ are connected to the two different legs of the modules and the ground resistance $\mathrm{Rg}$ is connected to the mutual point ' 0 '. However, the three output terminals such as phase $V_{a}$, phase $V_{b}$ and phase $V_{c}$ are connected to the L-branch of the inductor for change square wave to modify sinusoidal wave. 
To design the PSI module is performed by 10 IGBT/Diodes switches connected in series (each module) for improving system output current. Two modules connected in series are called half phase inverter, and three half phase are added for three phase inverters. In addition, the pulse generator is used to operate the IGBT/Diodes switches. Six modules are required six gate pulses which are $G_{1}, G_{2}, G_{3}, G_{4}, G_{5}$ and $G_{6}$. In this design are carried out using eight switching combinations as shown in Table 1. If the module turns 'ON' than the logic ' 1 ' is a positive signal that applied at the gate input. It turns 'OFF' when the logic ' 0 ' and a ' 0 ' signal is applied to the gate input. The device is in the OFF state when the gate voltage is negative. The state of module $1=$ module $3=$ module 5 is ' $O N$ ' condition. Consequently, the other switches like module 2 ' = module 4'= module 6' are 'OFF' state [13].

Table 1. Inverter Switching Mathods

\begin{tabular}{cccccc}
\hline Module 1 & $\begin{array}{c}\text { Module 3 } \\
\text { Module 2' }\end{array}$ & $\begin{array}{c}\text { Module 5 } \\
\text { Module 4' }\end{array}$ & $\begin{array}{c}\text { Module 6' } \\
\text { Moda }\end{array}$ & $V_{b}$ & \\
\hline 0 & 0 & 0 & $-\mathrm{Vdc} / 2$ & $-\mathrm{Vdc} / 2$ & $-\mathrm{Vdc} / 2$ \\
0 & 0 & 1 & $-\mathrm{Vdc} / 2$ & $-\mathrm{Vdc} / 2$ & $+\mathrm{Vdc} / 2$ \\
0 & 1 & 1 & $-\mathrm{Vdc} / 2$ & $+\mathrm{Vdc} / 2$ & $+\mathrm{Vdc} / 2$ \\
1 & 0 & 0 & $+\mathrm{Vdc} / 2$ & $-\mathrm{Vdc} / 2$ & $-\mathrm{Vdc} / 2$ \\
1 & 0 & 1 & $+\mathrm{Vdc} / 2$ & $-\mathrm{Vdc} / 2$ & $+\mathrm{Vdc} / 2$ \\
1 & 1 & 0 & $+\mathrm{Vdc} / 2$ & $+\mathrm{Vdc} / 2$ & $-\mathrm{Vdc} / 2$ \\
1 & 1 & 1 & $+\mathrm{Vdc} / 2$ & $+\mathrm{Vdc} / 2$ & $+\mathrm{Vdc} / 2$ \\
0 & 0 & 0 & $-\mathrm{Vdc} / 2$ & $-\mathrm{Vdc} / 2$ & $-\mathrm{Vdc} / 2$ \\
\hline
\end{tabular}

In the case of IGBT turns on, then the collector-emitter voltage is positive, greater than $\mathrm{V}_{f}$ and the positive signal $(\mathrm{g}>0)$ must be applied to the gate input. In the case of IGBT turns off, collector-emitter voltage is positive and zero signal $(\mathrm{g}=0)$ is applied to the gate input. The IGBT device is in off state if the collector-emitter voltage is negative. Therefore, they are usually used with an antiparallel diode. The IGBT block contains a series $R_{s}$ and $C_{s}$ snubber circuit, which is connected in parallel with the IGBT device between terminals $\mathrm{C}$ and $\mathrm{E}$ as shown in Figure 3.

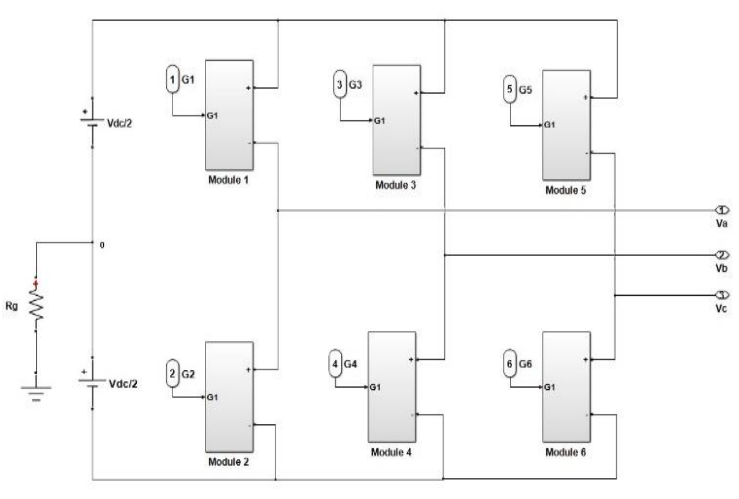

Figure 2. The switching modules arrangement for the $3 \varphi \mathrm{PSI}$ system

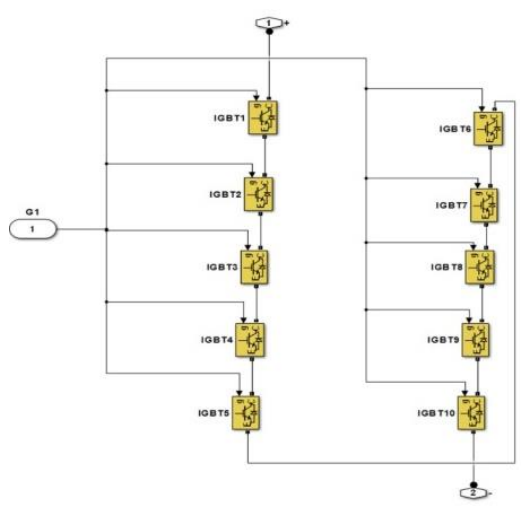

Figure 3. The IGBTs/diode switche arrangement of the PSI system

\section{Design of A Zero-Crossing Circuit}

Zero crossing circuit is performed to determine the phase angle of microgrid and inverter with the required fundamental frequency as shown in Figure 4. From the microgrid, three reference sample voltage $V_{a}^{\prime}, V_{b}^{\prime}$ and $V_{c}$ ' are taken for the sample circuit. This sample circuit then generated two type of voltage sample signal. One type is DC voltage that operated the DC component circuit and another type is sample voltage signal, mentioning by $S_{a}, S_{b}$ and $S_{c}$ which pass through the zero-crossing circuit. The main job of the zero-crossing circuit is to detect the zero-crossing point for phase angle and also to generate the zero-crossing sample $Z_{a}, Z_{b}$ and $Z_{c}$. After that, VSC utilizes these three zero crossing sample signal to generate six 
pulses such as $G_{1}, G_{2}, G_{3}, G_{4}, G_{5}$ and $G_{6}$. Zero crossing sensors is utilized to identify the phase angle as shown in Figure 5.

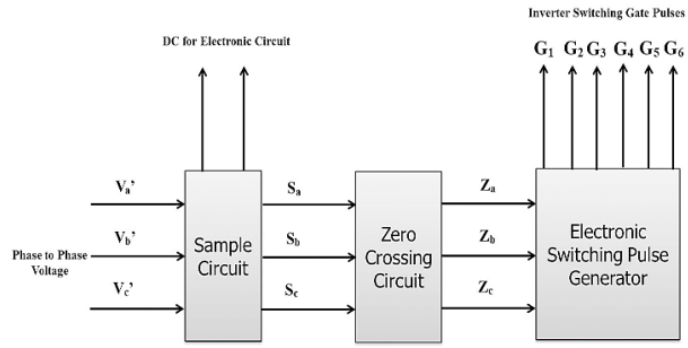

Figure 4. The block diagram of the zerocrossing circuit

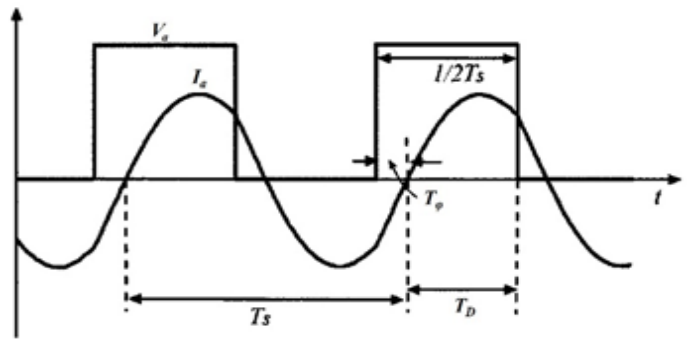

Figure 5. Voltage and current waveforms of half-phase switching PSI system

When the IGBT turn ON and turn OFF the low to the high side, the zero crossing to detect the desired phase. Then, the phase current can be varied from $0^{\circ}, 180^{\circ}$ and $360^{\circ}$ [13]. Where, the control variable is $T_{D}$, the phase angle command to current phase is $\varphi_{\text {res }}$ and the time response of current phase is $T_{\varphi}$ shown in Equations (1-5).

$T_{D}+T_{\varphi}=\frac{T_{S}}{2}$

$T_{D}=\frac{T_{S}}{2}-\varphi_{\text {ref }} \times \frac{T_{S}}{360^{0}}$

Where,

$T_{D}=\frac{T_{S}}{2}(2-\alpha)$

$T_{D}[\mathrm{n}]=\frac{T_{S}[n-1]}{4}(2-\alpha[\mathrm{n}])$

Again,

$$
\begin{array}{cc}
\alpha[\mathrm{n}]=\frac{\varphi_{\text {ref }}[n]}{90^{0}} & \text { When } 0 \leq \alpha[\mathrm{n}] \leq 1 \\
T_{D}[\mathrm{n}]=\frac{T_{S}[n-1]}{4}\left[\frac{\left(2^{S}-1\right)+\left(2^{S}-1-\alpha_{1}[n]\right.}{2^{S}}\right] &
\end{array}
$$

Where, $S$ is the number of sample in the zero-crossing phase command and $\alpha_{1}[n]=0$ parallels to $0^{0}$ while $\alpha_{1}[n]=2^{S}-1$ parallels to $90^{\circ}$. For a large $n$, this error can be avoided.

\section{Output LCL Filter Design}

A simple, three-pole, low-pass filter is often used to reduce switching ripple current and increasing phase may cause oscillations [14]. In this design, LCL filters have been employed to reduce DC ripple current and higher harmonic distortion. Figure 6 shows that the output LCL filter, where inductor $L_{1}$ is connected to the inverter side, inductor $L_{2}$ is connected to the microgrid-side and $C_{1}$ is a capacitor. The inverter output voltage $\left(\mathrm{V}_{\mathrm{L}-\mathrm{L}}\right.$ and $\left.\mathrm{V}_{\mathrm{p}}\right)$, inverter input voltage $\left(\mathrm{V}_{\mathrm{DC}}\right)$ microgrid frequency $\left(f_{\text {microgrid }}\right)$, rated active power $\left(\mathrm{P}_{\mathrm{n}}\right)$, resonance frequency $\left(R_{f}\right)$ and switching frequency $\left(f_{s w}\right)$ are required for the lowpass filter design.

The Equations (6) and (7) are defined as base capacitance and impedance which will be referred to the percentage of the base values [15]. To design the filter capacitance, a variation of the maximum power factor is taken $5 \%$ which value has been observed by the microgrid.

$C_{b}=\frac{1}{\omega_{g} Z_{b}}$ 


$$
Z_{b}=\frac{E_{n}^{2}}{P_{n}}
$$

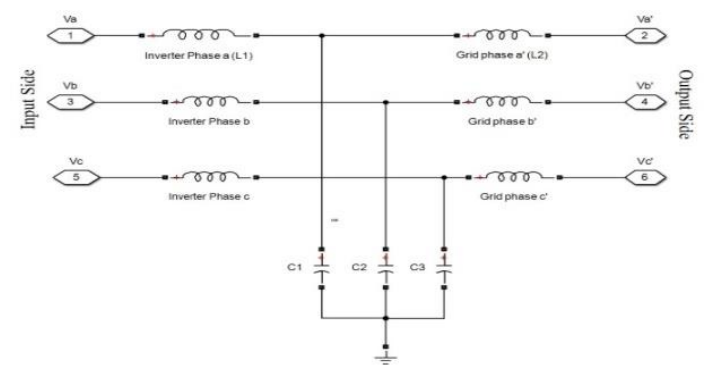

Figure 6. LCL filter circuit connection for $3 \varphi$ PSI system

This factor indicates system base impedance is adjusted to $\mathrm{Cf}=0.05 \mathrm{C}_{\mathrm{b}}$. Higher design factor may be used to compensate the inductive reactance of the filter shown in Equation (8) [16].

$\Delta I_{L \max }=\frac{V_{D C}}{6 f_{S w} L_{1}}$

Also, the filter parameters are $10 \%$ of the ripple rated current shown in Equation (9-11).

$\Delta I_{\text {Lmax }}=0.1 I_{\text {Lmax }}$

where,

$I_{\text {Lmax }}=\frac{P_{n} x \sqrt{2}}{3 V_{p}}$

$L_{1}=\frac{V_{D C}}{6 f_{s w} L_{1}}$

The ratio ( $r$ ) is constant for the both side inductance shown in Equation (12)

$L_{2}=r L_{1}$

$R_{f}$ is the resistor with the series capacitor decreases the ripple current on the switching frequency [5]. The output LCL filter capacitance is assumed by the following Equation (13-14).

$\omega_{\text {res }}=\sqrt{\frac{L_{1}+L_{1}}{L_{1} L_{2} C_{f}}}$

$R_{f}=\frac{1}{3 \omega_{\text {res }} C_{f}}$

In Equations (15) the total harmonic distortion has been calculated by the square root of $3^{\text {rd }}$ to the $\mathrm{n}^{\text {th }}$ harmonic current over fundamental harmonic current [4].

$T H D=\frac{\sqrt{I_{3}^{2}+I_{5}^{2}+\cdots+I_{n}^{2}}}{I_{1}^{2}} \times 100 \%$

Where, the fundamental harmonic is $I_{1}$, the $3^{\text {rd }}$ harmonic current is $I_{3}$, the $n^{\text {th }}$ harmonic current is $I_{n}$. 


\section{Transformer Design}

The three-phase $\mathrm{Y}-\Delta$ transformer circuit diagram that shown in Figure 7 . To design the transformer, it is considered that line-to-line voltages on the secondary windings are directly proportional to the primary windings through the turns ratio [17]. The transforms are schematically rotated by $180^{\circ}$ from each other to represent an $180^{\circ}$ electrical displacement in the voltages. The voltage labels on the individual coils correspond to the labels. In this case, the turns ratio is divided by $\sqrt{ } 3$ and the secondary phase lags by $30^{\circ}$ [4], [1].

$V_{2 a}^{\prime}=\frac{N_{2}}{N_{1}} V_{1 a}^{\prime}$

$V_{2 b}^{\prime}=\frac{N_{2}}{N_{1}} V_{1 b}^{\prime}$

$V_{2 c}^{\prime}=\frac{N_{2}}{N_{1}} V_{1 c}^{\prime}$

$V_{a b}^{\prime}=\frac{N_{2}}{N_{1}} V_{A B}^{\prime} \angle-30^{\circ}$

From Equations (16-18) as well as connection diagram of Figure7, the derivation of the transformer $\mathrm{Y}-\Delta$ Equation (30-22) has done. For A-B-C sequence, the transformer primary voltages can be followed by

$V_{1 a}^{\prime}=V_{r m s} \angle 0$

$V_{1 b}^{\prime}=V_{r m s} \angle-180$

$V_{1 c}^{\prime}=V_{r m s} \angle 360$

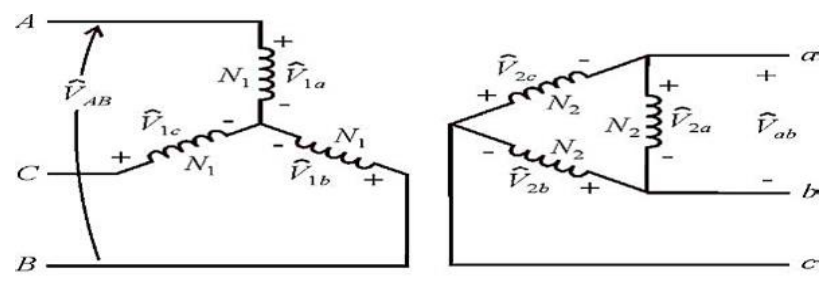

Figure 7. Basic connection of a $3 \varphi \mathrm{Y}-\Delta$ transformer

\section{Microgrid Systems}

The PSI microgrid has designed in MatLab, which circuit diagram presented in Figure 8. Those system design parameters are: zero sequence inductances, zero sequence capacitances, positive inductances, line length and the frequency used for RLC specification is the nominal system frequency which is $60 \mathrm{~Hz}$. However, in parameter selection time, the zerosequence inductance and capacitances cannot be made zero, because it would result in an invalid propagation speed computation [18]. Table 2 represented the microgrid selection parameters are measured while due to negative VAR, capacitive reactive power is equal to ' 0 '.

Table 2. Microgrid parameters

\begin{tabular}{ll}
\hline \multicolumn{1}{c}{ Name of the Parameters } & \multicolumn{1}{c}{ Value } \\
\hline The nominal phase to phase voltage $\left(\mathrm{V}_{\mathrm{n}}\right)$ & $25 \mathrm{e}^{3} \mathrm{Vrms}$ \\
Number of phases $(\mathrm{N})$ & 3 \\
Frequency $(\mathrm{f})$ & $60 \mathrm{~Hz}$ \\
Load $(\mathrm{R})$ & $250 \mathrm{~kW}, 2 \mathrm{MW}, 30 \mathrm{MW}$ and $2 \mathrm{MVAR}$ \\
Positive zero sequence resistance $\left(\mathrm{r}_{1}\right.$ and $\left.\mathrm{r}_{0}\right)$ & $0.12 \Omega / \mathrm{km}$ and $0.42 \Omega / \mathrm{km}$ \\
Inductance $\left(\mathrm{I}_{1}\right.$ and $\left.\mathrm{I}_{0}\right)$ & $1.35 \times 10^{-3} \mathrm{H} / \mathrm{km}$ and $4 \times 10^{-3} \mathrm{H} / \mathrm{km}$ \\
Capacitance $\left(\mathrm{C}_{1}\right.$ and $\left.\mathrm{c}_{0}\right)$ & $11.8 \times 10^{-9} \mathrm{~F} / \mathrm{km}$, and $5.21 \times 10^{-9} \mathrm{~F} / \mathrm{km}$ \\
Line lengths $(\mathrm{D})$ & $20 \mathrm{~km}$ and $10 \mathrm{~km}$ \\
Inductive reactive power $(\mathrm{QL})$ & $2 \times 106 \mathrm{VAR}$
\end{tabular}

IJEEI Vol. 5, No. 4, December 2017: $285-294$ 


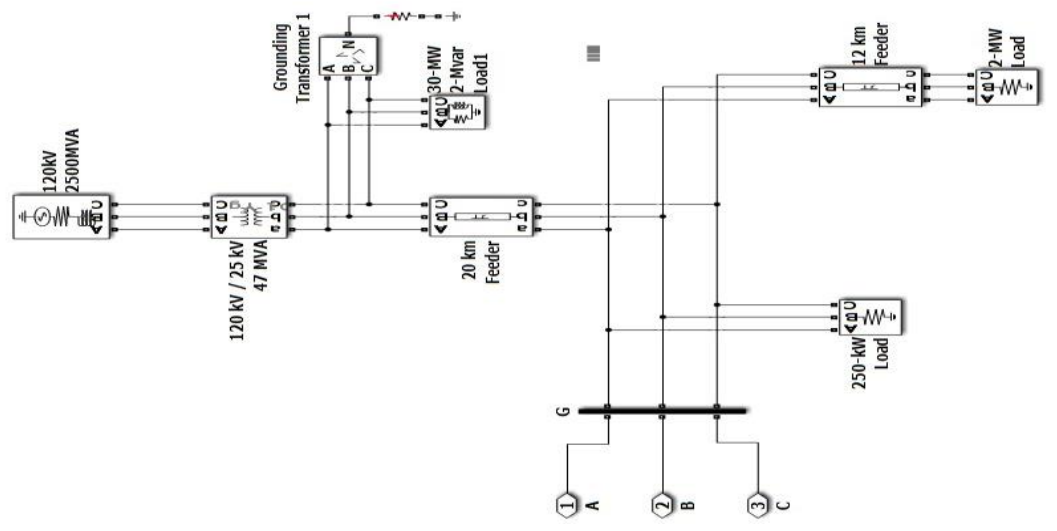

Figure 8. PSI connected MATLAB equivalent circuir

\section{Results and Discussion}

To validate the designed voltage source zero crossing controller for microgrid PS inverter, this design is simulated in MATLAB2016a/Simulink. PSI for microgrid connection is developed based on two conditions: with and without filtering condition. Series switching based IGBT modules is used to increase the output current and balance the microgrid voltage. The input voltage $\pm 5000 V_{D C}$ is converted into $\pm 250 e^{3} \mathrm{Vpp} A C$. Figure 9 shows the IGBT/Diodes collector to emitter voltage.

It was observed that the output voltage of the IGBT/Diodes is almost $1000 \mathrm{~V}$ and one module can be operated by $10000 \mathrm{~V}$. Figure 10 shows the IGBT/Diode operating feedforward current for module one and module two. During the simulation, these modules were handled up to $30 \mathrm{~A}$ operating current. If the operating current is higher, then modules cannot sustain this current.

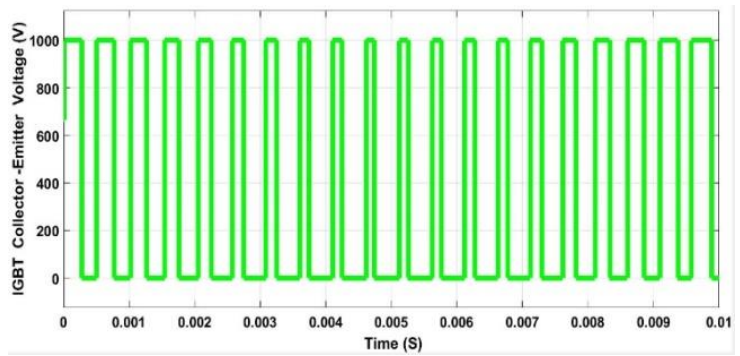

Figure 9. The IGBTs/diodes voltage $\mathrm{V}_{\mathrm{CE}}$

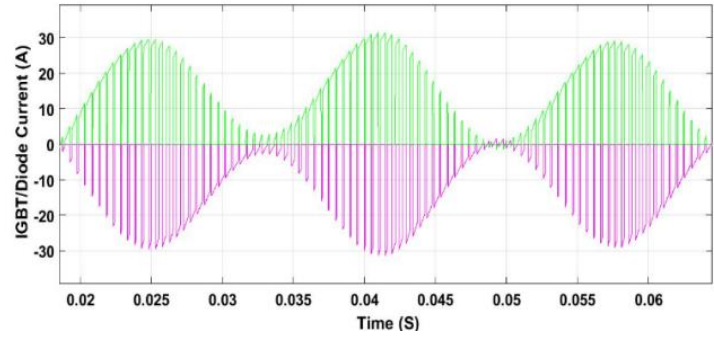

Figure 10. The forward current IF of the IGBTs/diodes

The zero-crossing voltage source controller has been utilized to operate the electronic switches and synchronized the inverter output phase and microgrid phase. Figure 11 illustrated that the simulation results with the distorted waveform of inverter output voltage and current to be a phase to ground voltage are $V_{a}=V_{b}=V_{c}=3482 V p$, phase to ground current is $I_{a}=I_{b}=I_{c}=30 A$ (peak) and the fundamental frequency $60 \mathrm{~Hz}$. Form the voltage and current wave; it is observed that output current at every point has cut the voltage waveform when current is in positive or negative edge; this happens due to zero crossing technique. 


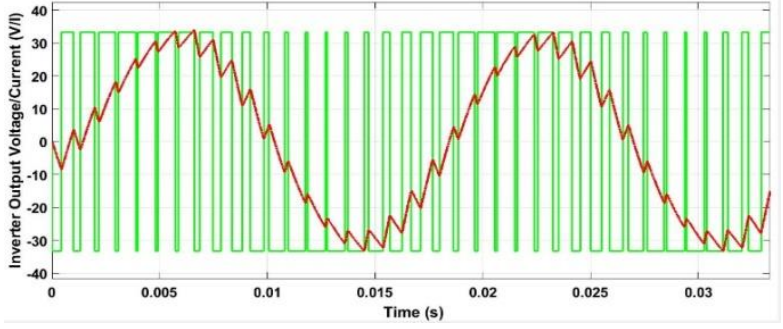

(a)

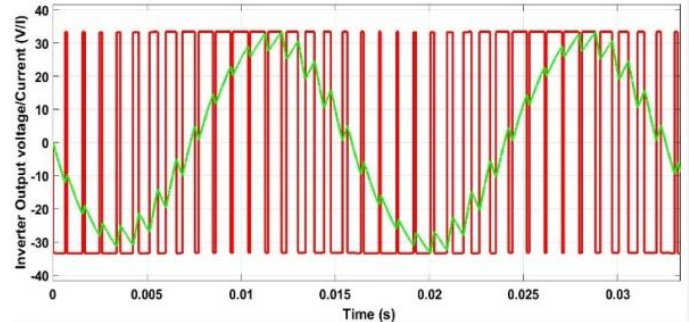

(b)

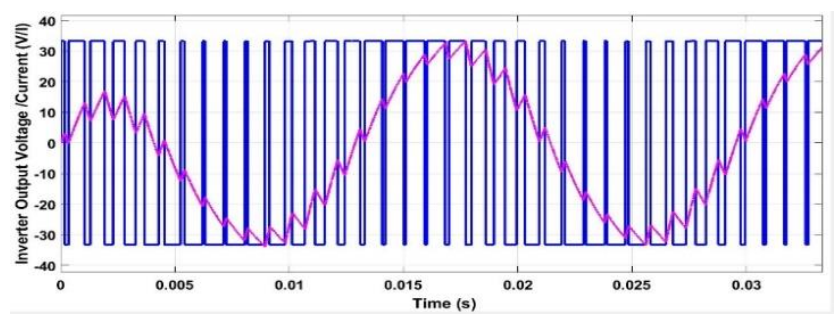

(c)

Figure 11. Inverter output voltage and current (a) $V_{a} \& I_{a}$, (b) $V_{b} \& I_{b}$, and (c) $V_{c} \& I_{c}$

The simulation result is shown in Figure 12 is about LCL output phase to the ground voltage and current waveform with filtering condition. It is found the output voltage $V_{a b c}=1735.06 \mathrm{Vp}$ and current $\mathrm{I}_{\mathrm{abc}}=400$ Apeak whereas the fundamental frequency $f_{s w}=60 \mathrm{~Hz}$, sampling time $0.035 \mathrm{~s}$ and the number of sampling per cycle is 3240 .

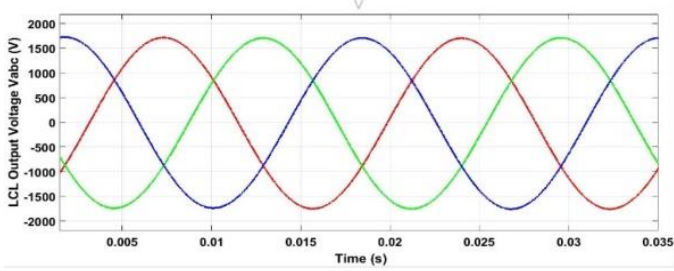

(a)

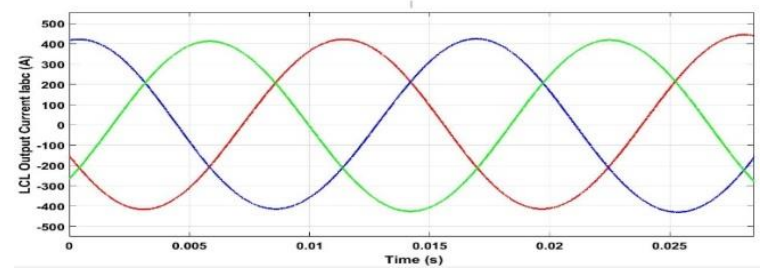

(b)

Figure 12. LCL filter output waveforms of the $3 \varphi \mathrm{PSI}$, (a) voltage $\mathrm{V}_{\mathrm{abc}}$ and (b) current $\mathrm{I}_{\mathrm{abc}}$

The microgrid phase to the ground voltage and current waveform are shown in Figure 13. The transmission voltage approximately $2 \times 10^{4} \mathrm{kV}$ (peak) is purely sinusoid, feeder line current is around $60 \mathrm{~A}$ (peak to peak) and microgrid frequency is $60 \mathrm{~Hz}$.

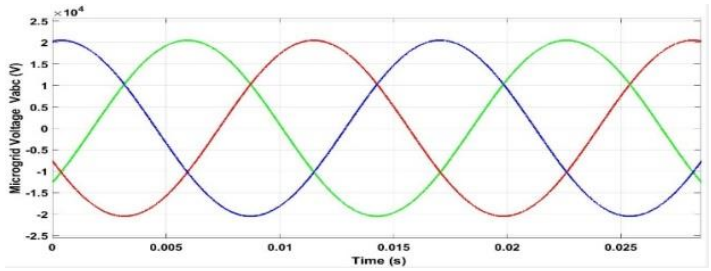

(a)

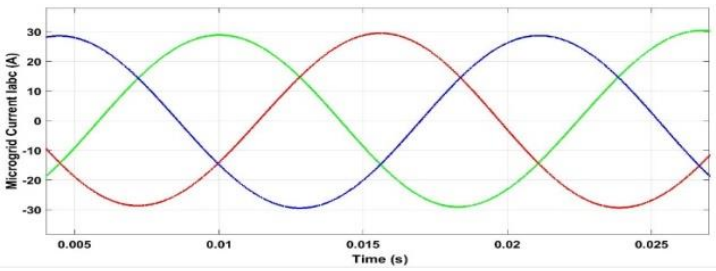

(b)

Figure 13. $3 \varphi \mathrm{PSI}$ system microgrid waveforms, (a) voltage $\mathrm{V}_{\mathrm{abc}}$ and (b) current $\mathrm{I}_{\mathrm{abc}}$ 
Figure 14 demonstrated that the magnitude and phase of LCL output voltage and current waveform. The three-different colors such as red, green and blue are represented the phase to ground voltage $\mathrm{V}_{\mathrm{a}}, \mathrm{V}_{\mathrm{b}}$ and $\mathrm{V}_{\mathrm{c}}$. The simulation result of the inverter phase angles with filtering condition is $\mathrm{V}_{\mathrm{ab}}-\mathrm{V}_{\mathrm{bc}}$ of $12.75^{\circ}, \mathrm{V}_{\mathrm{bc}}-\mathrm{V}_{\mathrm{ca}}$ of $167.26^{\circ}, \mathrm{V}_{\mathrm{ca}}-\mathrm{V}_{\mathrm{ab}}$ of $347.25^{\circ}$. On the other hand, the magnitude and phase of LCL output phase to ground Vabc is almost same of labc. During this case, the phase angle increases while the harmonic distortion is also increased. When the signal passed through the filter to shift the phase, but harmonic is reduced. Form Figure 14, it is found the output THD current $-29.54 \mathrm{~dB}$ (THD =1.81\%), where $60 \mathrm{~Hz}$ fundamental frequency.

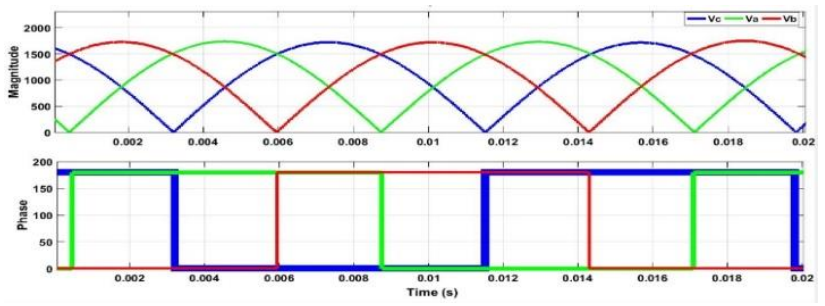

(a)

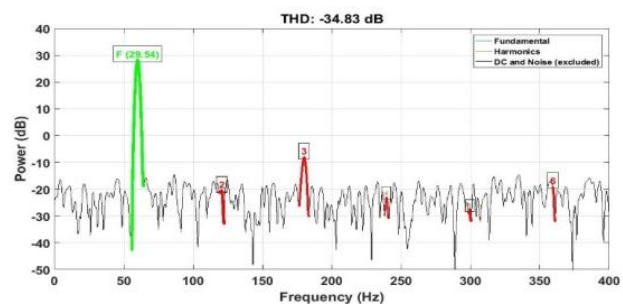

(b)

Figure 14. LCL filter output power, (a) magnitude and phase in time-domine and (b) magnitude in frequency-domain

Figure 15 has presented that the microgrid output voltage waveform, the phase angles are $\mathrm{V}_{\mathrm{ab}}-\mathrm{V}_{\mathrm{bc}}$ of $3.95^{\circ}, \mathrm{V}_{\mathrm{bc}}-\mathrm{V}_{\mathrm{ca}}$ of $177.96^{\circ}, \mathrm{V}_{\mathrm{ca}}-\mathrm{V}_{\mathrm{ab}}$ of $358.06^{\circ}$. Proposed inverter phase is almost same as microgrid phase due to zero crossing in which the phase error is $3.22^{\circ}$.

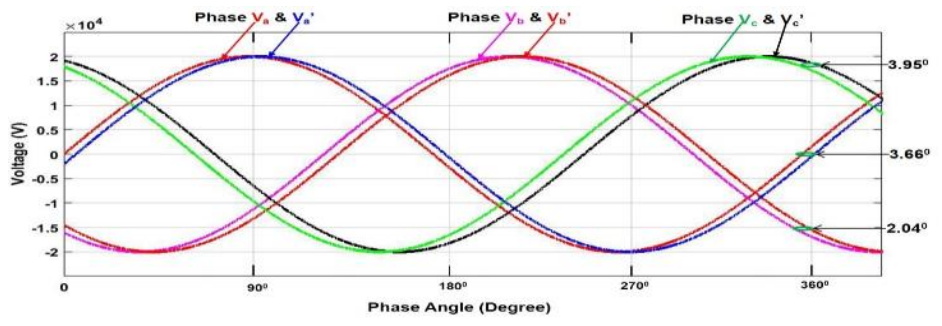

Figure 15. $3 \varphi$ phase microgrid voltage wave synchronizaton and waves

\section{Conclusion}

In this design, a phase synchronous inverter (PSI) is modelled that have been able to increase the inverter output efficency. This improvement has done with the aid of zero crossing voltage source controller. To overcome the synchronize issue in microgrid system, a zerocrossing method has presented which synchronous performance is very high; there performance is evaluated by MatLab simulation. The overall system efficiency is $97.35 \%$, and the phase angle are $3.66^{\circ}, 2.04^{\circ}$ and $3.95^{\circ}$; lower than the maximum allowable angle (Phase angle $<5^{\circ}$ ) as per IEEE standard.

\section{Acknowledgements}

This research has been supported by the Malaysian Ministry of Education through the Fundamental Research Grant Scheme under the project ID: FRGS15-190-0431 and the Malaysian Ministry of Science and Technology through the eScienceFund under the project ID: SF14-010-0060. 


\section{References}

[1] Rahman T, Ibrahimy MI, Motakabber SM, Mostafa MG. Simulation and Evaluation of A Phase Synchronous Inverter for Micro-Grid System. InThe Intl. Postgraduate Conference on Engineering Research (IPCER). Kuala lumpur. 2016; 11(1): 27-28.

[2] Rahman T, Motakabber SM, Ibrahimy MI. Phase Synchronous Inverter for Microgrid System. In Computer and Communication Engineering (ICCCE). Kuala Lumpur, 2016: 167-171.

[3] Rahman T, Motakabber SM, Ibrahimy MI. Low noise inverter for poly phase microgrid system. In Computer and Communication Engineering (ICCCE). Kuala Lumpur, 2016: 172-176.

[4] Rahman T, Motakabber SM, Ibrahimy MI. Design of a switching mode three phase inverter. In Computer and Communication Engineering (ICCCE). Kuala Lumpur, 2016: 155-160.

[5] Tang Y, Loh PC, Wang P, Choo FH, Gao F, Blaabjerg F. Generalized design of high performance shunt active power filter with output LCL filter. IEEE Transactions on Industrial Electronics. 2012; 59 (3): 1443-52.

[6] Rahman T, Motakabber SM, Ibrahimy MI. Three Phase Three Layer Phase Synchronous Inverter for Microgrid System. In Computer and Communication Engineering (ICCCE). Kuala Lumpur, 2014: 4447.

[7] Yin Y, Zane R. Digital phase control for resonant inverters. IEEE power electronics letters. $2004 ; 2$ (2): 51-3.

[8] Reznik A, Simoes MG, AI-Durra A, Muyeen SM. \$ LCL \$ filter design and performance analysis for grid-interconnected systems. IEEE Transactions on Industry Applications. 2014; 50 (2): 1225-32.

[9] Rodríguez P, Luna A, Candela I, Mujal R, Teodorescu R, Blaabjerg F. Multiresonant frequencylocked loop for grid synchronization of power converters under distorted grid conditions. IEEE Transactions on Industrial Electronics. 2011; 58(1): 127-38.

[10] González-Espín F, Figueres E, Garcerá G. An adaptive synchronous-reference-frame phase-locked loop for power quality improvement in a polluted utility grid. IEEE Transactions on Industrial Electronics. 2012; 59(6): 2718-31. 